\title{
Inheritable destabilization of several phenotypic characters in amoebae and ciliates
}

\author{
Zoya I. Uspenskaya \\ Institute of Cytology, Russian Academy of Sciences, St. Petersburg, Russia
}

| Submitted March 16, 2020| Accepted April 16, 2020|

\begin{abstract}
Summary
In the course of many years of genetic research conducted by various researchers of amoebae Amoeba proteus and ciliates Dileptus anser, a particular type of hereditary variation called instability of traits has been described. The new previously unnoticed ability of the known antibiotic actinomycin D to induce this type of hereditary variability in these protists was revealed. For a number of features, this variability can be considered epigenetic, not caused by any mutation in DNA. Therefore, actinomycin $\mathrm{D}$ can be viewed as an inducer of the inherited changes of epigenetic nature, i.e. «epimutagen».
\end{abstract}

Key words: Amoeba proteus, Dileptus anser, genetic variation, inheritable destabilization of characters, genetics, actinomycin $\mathrm{D}$, epigenetics

\section{Introduction}

The inheritance of traits in the agamic freshwater amoeba Amoeba proteus (Amoebozoa, Tubilinea) and the ciliates Dileptus anser (Rhynchostomatia, Litostomatea) (Adl et al., 2012) have been studied for many decades in the Laboratory of Cytology of Unicellular Organisms at the Institute of Cytology, Russian Academy of Sciences. Specifically, we conducted genetic research on two biologically different and phylogenetically distant protistan species and discovered an unusual type of hereditary variation. This review presents the results of the study of a peculiar type of hereditary variability the inherited instability for a number of phenotypic characters, performed in the framework of the above mentioned research program.

\section{Inheritable destabilization of characters in amoebae}

Since amoebae are agamic, we used microsurgical transplantation of nuclei for genetic research on these protists. We had at our disposal the collection of laboratory clones and clones isolated from natural populations (strains B, C, L and others). Many of those clones differed by some morphological, physiological or biochemical characters. The differences persisted over many years of culturing and, as shown in the nuclear transplantation experiments, were exclusively controlled by the nucleus (Yudin and Sopina, 1970; Yudin, 1982). Destabilization of some of those phenotypic characters was first found in clones descended from heterokaryons as an inheritable result of cytoplasm-mediated mutual

doi:10.21685/1680-0826-2020-14-2-1 
influence of the nuclei (Kalinina and Yudin, 1964; Yudin, 1973). The initial material used in those first studies was represented, e.g., by strains $\mathrm{X}$ and $\mathrm{Y}$, which showed an inheritable difference in a marker character. Diheterokaryons $X_{n} Y_{n c}$ and $Y_{n} X_{n c}(n-$ nucleus, $\mathrm{c}-$ cytoplasm) and dihomokaryons $\mathrm{X}_{\mathrm{n}} \mathrm{X}_{\mathrm{nc}}$ and $\mathrm{Y}_{\mathrm{n}} \mathrm{Y}_{\mathrm{nc}}$ were obtained. These dikaryons were cut into two uninucleate halves with a fine glass needle on the day 5 after they were obtained (but before their natural division) and a clone was grown from each half. After that, these clones were repeatedly and successively tested for the marker character.

The phenotype of both clones originating from a diheterokaryon changed in almost $100 \%$ of the cases. The changes occurred in both nuclei. They were manifested in the inheritable destabilization of the marker character, which was, as mentioned above, controlled by the nucleus. Successively tested samplings of amoebae from a destabilized clone demonstrated the phenotype of one or another of the "parent" strains in some cases, and some intermediate state of the character in some other cases (though it remained uncertain to what extent the behaviour of amoebae in a tested sampling was synchronous). The results of experiments of this kind involving two marker characters, resistance to methionine and resistance to ethanol, are shown in Fig. 1. Clones originating from dihomokaryons remained stable. It was shown that destabilization of the other nucleus-controlled characters arose in the same way.

It became clear rather soon that an inheritable destabilization of characters in amoebae may be caused not only by the mutual influence of the nuclei in heterokaryons but also by the diverse external impacts such as X-ray exposure, injections of total RNA obtained from amoebae of the same or a different strain, treatment with actinomycin D (AmD) or ribonuclease, etc. (Kalinina 1967, 1968, 1969; Yudin 1979, 1982; and others). Taken together, the data on the induced destabilization in amoebae allowed suggesting that in all the cases the researchers dealt with the same phenomenon. The data indicated that the arising changes were not associated with mutations since inheritable changes resulting in destabilization of the studied characters in amoebae always arose with a very high frequency (up to 100\%) under the impact of diverse and often undoubtedly non-mutagenic factors. It was hypothesized that inheritable characters that can be destabilized are under epigenetic control, and that the agents inducing inheritable destabilization act upon the mechanisms regulating the activity of
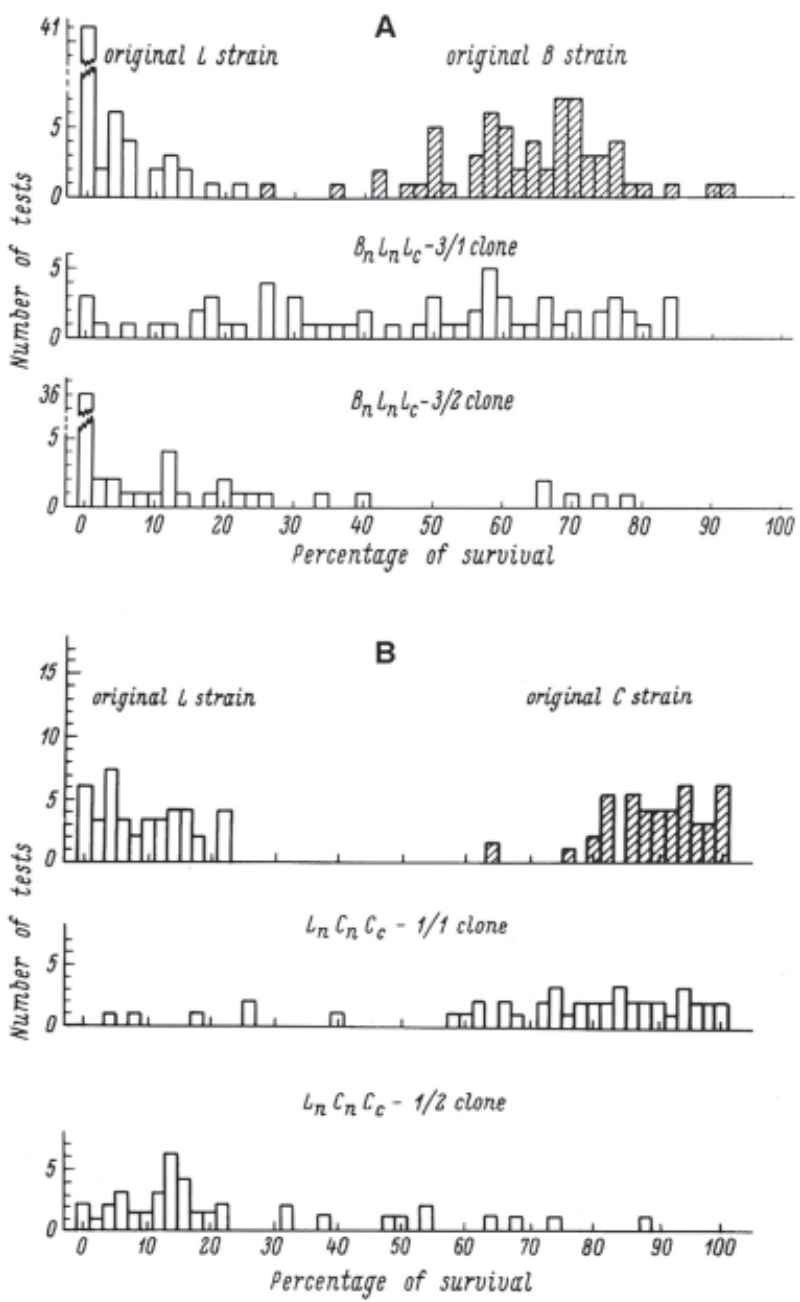

Fig. 1. Examples of inherited instability of traits in amoeba clones grown from mononuclear halves of a diheterokaryonic cell (from: Yudin 1967, modified). A - Resistance of amoebae to methionine (0.15 M, 18-20 h); B - resistance of amoebae to ethanol (7\%, $5 \mathrm{~min})$. $\mathrm{X}$-axis: number of amoebae survived of 50 cells taken in each test (in \%); Y-axis: number of tests that showed a given survival rate. $\mathrm{L}, \mathrm{B}$, and $\mathrm{C}-$ amoebae strains; $\mathrm{n}-$ nucleus, $\mathrm{c}-$ cytoplasm.

genetic material rather than on genetic material itself.

\section{Actinomycin D induces inheritable destabili- zation of characters in amoebae}

As already noted, inherited instability based on traits controlled by the nucleus can be induced in amoebas, in particular by treating them with $\mathrm{AmD}$, which is well known in experimental biology as a 
transcription inhibitor. The inhibition occurs due to the formation of a stable complex between $\mathrm{AmD}$ and DNA and the disruption of the DNA-dependent RNA synthesis (Hollstein, 1974; Sobell, 1985). As an example, we present here the results of the tests performed on the clones grown from AmD-treated amoebae (Yudin, 1979). Resistance to ethanol (survival after 5 min in 7\% ethanol; Yudin and Sopina, 1970) was used as a marker character. In this study, in order to reduce the duration of the experiment, clones were tested not several times successively but just once. Each clone to be tested for stability was used to establish several dozens of subclones cultivated in parallel. When the number of cells in each subclone was not less than 50, all those subclones were tested for resistance to ethanol simultaneously. If all the subclones showed the resistance typical of the initial strain $\mathrm{C}$, the clone was considered to be stable. If at least some of the subclones showed the resistance not characteristic of strain $\mathrm{C}$, the clone in general was considered to be unstable. Resistance to ethanol of the initial strain $\mathrm{C}$ in the course of the experiment was as follows: out of the 324 subclones tested, in one clone the survival amounted to $58 \%$, while in all other clones it amounted to $60-100 \%$, with the survival of 93\% subclones falling within the range of $80-100$ $\%$. Therefore, survival values of $60-100 \%$ were considered to be typical of strain $\mathrm{C}$.

Four out of the six clones tested showed destabilization (Table 1). The poorest survival values observed in these clones were much smaller than those observed in the control amoebae (strain C). Interestingly, we found no indications of a destabilizing effect of the antibiotic emetine $\left(10^{-4}\right.$ M, $24 \mathrm{~h}$ ) and cycloheximide ("Serva" Germany, $1000 \mu \mathrm{g} / \mu \mathrm{l}, 24 \mathrm{~h}$ ) tested in the same experiment. Destabilizing activity of AmD in amoebae was also shown in other experiments (Kalinina, 1968; Olenov, 1970; Uspenskaya and Yudin, 2017).

\section{Inheritable destabilization of characters in dilepti}

Mating type (MT) is a commonly studied character in sexual ciliates. MTs have been found in dozens of species from all ciliate classes (see for review: Miyake, 1996). Since MT systems, their genetic control and the ways in which they are inherited are quite diverse, their study opens promising vistas for comparative genetics. The ciliate Dileptus anser is an especially attractive
Table 1. Destabilizing effect of Actinomycin D (1000 $\mu \mathrm{g} / \mathrm{ml}, 2 \mathrm{~h}$ ) on C amoebae (from: Yudin, 1979, modified).

\begin{tabular}{|c|c|c|c|}
\hline \multirow{2}{*}{ Clones } & \multirow{2}{*}{$\begin{array}{c}\text { Number of sub- } \\
\text { clones tested }\end{array}$} & \multicolumn{2}{|c|}{$\begin{array}{c}\text { Number of subclones with sur- } \\
\text { vival rate in } 7 \% \text { ethanol }\end{array}$} \\
\cline { 3 - 4 } & & $<60 \%$ & $60-100 \%$ \\
\hline 1 & 49 & 12 & 37 \\
\hline 2 & 43 & 10 & 33 \\
\hline 3 & 71 & 6 & 65 \\
\hline 4 & 68 & 4 & 64 \\
\hline 5 & 24 & 0 & 24 \\
\hline 6 & 40 & 0 & 40 \\
\hline
\end{tabular}

research object because it is one of the relatively uncommon species excreting specific signal products - mating pheromones triggering the sexual process. The MT of such an organism is determined by the pheromones it excretes and the pheromone receptors it bears on the cell surface (Yudin et al., 1990).

Three MTs have been found in Dileptus anser. Most individuals isolated from natural populations form clones belonging, as revealed by crossing with tester clones, to one of the three MTs. All these MTs are stably inherited in a series of vegetative generations over many years of cultivation under laboratory conditions. Similarly to many other ciliates, dilepti are usually sexually immature after conjugation, that is, unable to conjugate with mature dilepti with complementary MTs (Bleyman, 1971, 1972; Nanney, 1980; Takagi, 1988). After a certain number of cell divisions they become partly mature (adolescent), i.e. they can conjugate to only one of the two complementary MTs. Finally, they become fully mature.

The inheritance of MT during crossing in sexual generations was studied with the help of hybridological analysis. The results indicated that this character was inherited synclonally and that it was controlled by a single mat locus with three alleles showing the peck-order dominance: mat $^{1}>$ mat $^{2}>$ mat $^{3}$ (Yudin and Afon'kin, 1987). However, data that did not fit the above scheme have gradually accumulated. Crossings of various dilepti clones with all the three MTs were performed for several years. On the one hand, some of the crosses continued to demonstrate a synclonal inheritance of this character in sexual generations, peck-order dominance of the alleles and an MT segregation not significantly different from 1:1. In other words, we observed, as before, a more or less evident monofactorial Mendelian behaviour of the 
character whose inheritance was under direct genetic control (Siegel, 1970). On the other hand, several crosses showed more or less considerable deviations from this scheme (Uspenskaya and Yudin, 2016, Uspenskaya, 2019). The anomalous features of these exconjugant clones were as follows: (1) their maturation was delayed as compared to other clones; (2) they temporarily reverted to immature or adolescent state, that is, destabilization of the maturity state was observed; (3) some MTs found in them could not be predicted by the scheme described above. Examples of the behaviour of these "irregular" clones are given in Table 2. Out of 142 exconjugant clones tested, which were obtained in eight different crosses, a change of MT (that happened once or twice) was noted in 40 clones (28\%). In 30 cases out of 45 we managed to register that a change of MT was accompanied by a transition to the state of immaturity or adolescence. Changes of MT occurred in all possible directions though with a different probability (Uspenskaya and Yudin, 2003; Yudin and Uspenskaya, 2006).

It was clear that the causes of unstable MT differentiation in Dileptus anser could have different nature. An epigenetic component of the hereditary MT control could not be ruled out. Based on this, we hypothesised that the mat locus in dilepti has a complex nature, i.e. contains genetic potentiality for all the three MTs (Yudin and Uspenskaya, 2007), similarly to the complex MT locus in the ciliate Tetrahymena thermophila (Cervantes et al., 2013). In the course of maturation of an exconjugant dilepti clone, this complex locus undergoes an epigenetic differentiation in the macronucleus (Ma), resulting in the expression of one of the three genetic potentialities encoded in it: an MT-determining "epiallele" of this locus arises. These assumptions help us to explain MT changes in young exconjugant clones as well as deviations from the Mendelian behaviour of the character in crosses. As for the Mendelian behaviour of MT, it appears to be possible only if the complex locus mat can stably differentiate in the generative nucleus, the micronucleus (Mi), resulting in a stable micronuclear epiallele: mat $^{1}$, mat $^{2}$ or mat ${ }^{3}$.

\section{Actinomycin D induces inheritable destabili- zation of mating type in dilepti}

If MT determination in dilepti has an epigenetic nature, mature clones may retain in their Ma a genetic potentiality for all three MTs. In such a case
Table 2. Changes of mating type in just matured exconjugant clones of Dileptus anser (several examples (from: Yudin and Uspenskaya, 2007, modified).

\begin{tabular}{|c|c|}
\hline Clone & $\begin{array}{l}\text { MT of the clone (Roman numerals) and period of } \\
\text { time after conjugation (in brackets, months) }\end{array}$ \\
\hline \multicolumn{2}{|c|}{$\begin{array}{l}\text { Progeny from the cross \# B (MT I) } \times \text { \# D (MT III); } \\
\text { a total of } 7 \text { clones obtained from this cross were tested }\end{array}$} \\
\hline $5-14$ & II $(5-6) \rightarrow$ IM $(9-10) \rightarrow$ I $(14-15) \rightarrow$ I $(19-20)$ \\
\hline $7-3$ & I $(5-6) \rightarrow$ IM $(9-10) \rightarrow$ II $(14-15) \rightarrow$ II $(19-20)$ \\
\hline $9-7$ & III $(9-11) \rightarrow(14-15) \rightarrow$ II $(19-20)$ \\
\hline $10-21$ & II $(5-6) \rightarrow$ IM $(9-10) \rightarrow$ III $(14-15) \rightarrow$ III $(19-20)$ \\
\hline \multicolumn{2}{|c|}{$\begin{array}{l}\text { Progeny from the cross } F_{1}(M T \text { II }) \times \# B(M T I) \text {; } \\
\text { a total of } 5 \text { clones obtained from this cross were tested }\end{array}$} \\
\hline $13-10$ & $\begin{array}{l}\text { I }(3-4) \rightarrow \text { IM }(5-6) \rightarrow \text { IM }(9-10) \rightarrow \text { AD }(14-15) \rightarrow \\
\text { II }(19-20)\end{array}$ \\
\hline \multicolumn{2}{|c|}{$\begin{array}{l}\text { Progeny from the cross } F_{1}(M T \text { II }) \times \text { \# D (MT III); } \\
\text { a total of } 5 \text { clones obtained from this cross were tested }\end{array}$} \\
\hline $14-2$ & $\begin{array}{l}\text { II }(3-4) \rightarrow \text { IM }(5-6) \rightarrow A D(9-10) \rightarrow \text { III }(14-15) \rightarrow \\
\text { II }(19-20)\end{array}$ \\
\hline $18-3$ & III $(9-10) \rightarrow$ II $(14-15) \rightarrow$ I $(19-20)$ \\
\hline $20-2$ & II $(9-10) \rightarrow A D(14-15) \rightarrow$ I $(19-20)$ \\
\hline
\end{tabular}

Notes: IM - immaturity (the clone does not mate with any one of three tester clones); $A D-$ adolescence (clone mates with only one of three tester clones); $\mathrm{F}_{1}$ - progeny from the cross \# B $\times$ \# D.

they can, in principle, change their MT. This idea was supported by the fact that MT changes in old laboratory clones could be induced by the antibiotic AmD. We would like to emphasize, again, that mature clones of dilepti, both isolated from natural populations and those cultured in the laboratory, usually retain an unchanged MT over many months and even years of observations. Deviations from this rule are very rare.

Our study showed that the destabilization of mature laboratory clones of dilepti, expressed in MT changes, was indeed possible. We used three laboratory clones of Dileptus anser: no. 3 (MT I), no. 13 (MT II) and no. 153 (MT III). The cells were kept for 3 days in a culture medium with AmD $(15 \mu \mathrm{g} / \mu \mathrm{l})$. Then the cells were rinsed and each single cell was used to establish a subclone. Altogether, 20 subclones of each clone were grown. Subclones of all three clones behaved in a similar manner. Some subclones developed a temporary state of immaturity, which could be more or less prolonged, while some showed a different MT than that of the initial clone; switching to all the MTs possible in dilepti was also recorded in the course of observations. These results are summarized in Table 3.

Thus, there are good reasons to think that AmD destabilizes the MT of mature clones of dilepti. It turns out that the genotype of a long-mature cell, 
Table 3. Changes in mating type of clone 153 (MT III) of Dileptus anser after the action of actinomycin D (15 $\mu / \mathrm{ml}, 3$ days) (from: Yudin and Ushpenskaya, 2009).

\begin{tabular}{|l|c|c|c|c|c|c|c|c|}
\hline $\begin{array}{l}\text { Subclo- } \\
\text { nes of } \\
\text { clone }\end{array}$ & \multicolumn{7}{|c|}{ Mating type of subclones at consecutive testing } \\
153 & $1-2$ & $3-4$ & $5-6$ & $7-8$ & $9-10$ & $11-12$ & $13-14$ & $>15$ \\
\cline { 2 - 8 } & & & & & \\
$153-1$ & III & - & - & I & I & dead & & \\
$153-2$ & III & & III & - & II & II & II & II \\
$153-3$ & II & - & - & - & I & I & I & I \\
$153-4$ & - & - & - & III & III & III & III & III \\
$153-5$ & III & III & III & III & III & III & III & III \\
$153-6$ & I & - & - & I & III & III & I & I \\
$153-7$ & III & - & - & - & - & II & - & II \\
$153-8$ & III & - III & - & - & - & dead & & \\
$153-9$ & - & - & - & II & II & II & II & II \\
$153-10$ & - & - & - & - & - & dead & & \\
$153-11$ & III & - & - & - & dead & & & \\
$153-12$ & III & - & - & III & III & III & III & III \\
$153-13$ & - & - & I & I & I & I & - & dead \\
$153-14$ & III & - & II & - & - & - & dead & \\
$153-15$ & - & - & III & II & III & - & II & II \\
$153-16$ & III & III & III & III & III & - & - & dead \\
$153-17$ & - & - & II & - & - & I & I & I \\
$153-18$ & III & III & III & III & III & III & III & III \\
$153-19$ & - & - & I & I & - & - & I & I \\
$153-20$ & - & II & II & II & - & II & II & II \\
\hline
\end{tabular}

Notes: The dash ( - ) indicates that subclone does not react with any of the three test clones (immaturity state). Bold font indicates cases of MT manifestation that are not characteristic of the initial clone 153.

which stably reproduces a given MT, has a hidden genetic potentiality for the other MTs, which may be realized under certain conditions. In a maturing exconjugant clone, a normal epigenetic differentiation of the mat locus in Ma is, for some reasons yet unknown, disrupted and the system switches to an inheritable destabilized regime.

\section{Conclusion}

Studies of non-Mendelian inheritance in protists provided numerous examples of epigenetic heredity based on various epigenetic mechanisms (Nanney, 1958, 1980; Beale and Preer, 2008). Some of these mechanisms are quite complex (see, e.g.: Kataoka and Mochizuki, 2011). In this study, we proceeded from the fact that in two entirely different protist species, an amoeba and a ciliate, the epigenetic mechanisms were involved in the control of several inheritable characters (resistance to ethanol and methionine in amoebae, mating type in dilepti). These mechanisms operated in such a way that the system either remained in one of the two or three alternative stable states ("epialleles") or switched to an oscillatory, unstable regime.
Importantly, it was not only the manifestation of a character over many vegetative generations that were inherited in destabilized clones of amoebae or ciliates. Once destabilization has been induced, it was inherited as well. In other words, an epigenetic system switched from a stable differentiation regime into an inheritable oscillating regime. Despite the long-term observations of destabilized clones, no reversions to stabilization were observed, neither in amoebae nor in dilepti.

There are few, if any, data on the mutagenic activity of AmD. If it is a mutagen, it is a very weak one (Fishbein, 1979; Fishbein et al., 1970; Koba and Konopa, 2005). On the other hand, it is highly probable that $\mathrm{AmD}$, suppressing the synthesis of RNA and, thus, the synthesis of proteins, may disrupt normal regulatory associations in epigenetic contours, bringing about inheritable changes, "epimutations", of epigenetically controlled characters, in particular, their destabilization. In these cases AmD may be considered as an epimutagen, that is, an agent inducing inheritable changes not associated with mutations (Holliday and Ho, 2002; Maletskaia et al., 2006; Lamparska et al., 2012; Arai et al., 2015; Uspenskaya, 2018 and others).

In conclusion, it should be added that recent data characterise $\mathrm{AmD}$ as an agent of very versatile effects. AmD has been reported to be a potential replication inhibitor of the human immunodeficiency virus type 1 (HIV-1) due to AmD's ability to inhibit reserve transcription (Imamichi et al., 2003). Other results suggest that histone gamma-H2AX promotes binding of nuclear DNA helicase to transcriptionally stalled sites on chromosomal DNA (Mischo et al., 2005). Recent works link effects of $\mathrm{AmD}$ with use treatment. AmD significantly reversed DM1-associated (DM1-Myotonic dystrophy 1) splicing defects in a DM1 mouse model and did so within the currently approved human treatment range (Siboni et al., 2015). It was also shown that AmD activates the extrinsic pathway of apoptosis and acts synergistically with RG7787 to kill a variety of cancer cell lines and cause striking tumor regression in mice. AmD can interfere with ribosomal biogenesis and causes stabilization of P53 in the nucleolus (Liu et al., 2016). It was found that the action of AmD activates RNase L, which leads to subsequent changes in the cell cycle. In particular, activation of RNase L suppressed the tumor formation and the induction of lung cancer stem cells (Huijing et al., 2019). 


\section{Acknowledgments}

The research was funded by the Budgetary Program \# 0124-2019-0005 at the Institute of Cytology RAS.

\section{References}

Adl S.M., Simpson A.G.B., Lane C.E., Lukeš J., Bass D., et al. 2012. The revised classification of eukaryotes. J. Eukaryot. Microbiol. 59, 429-493.

Arai Y., Hayakawa K., Arai D., Ito R., Iwasaki Y., et al. 2015. Putative epimutagens in maternal peripheral and cord blood samples identified using human induced pluripotent stem cells. BioMed Res. Int. Article ID 876047. doi: 10.1155/2015/876047.

Beale G.H. and Preer J.R. 2008. Paramecium: genetics and epigenetics. CRC Press. Taylor and Francis Group, London, New York.

Bleyman L.K. 1971. Temporal patterns in the ciliated protozoa. In: Developmental aspects of the cell cycle. Academic Press, New York, pp. 67-91.

Bleyman L.K. 1972. A new spontaneous early mature mutant in Tetrahymena pyriformis. Genetics 71, s5-s6.

Cervantes M.D., Hamilton E.P., Xiong J., Lawson M.J., Yuan D., Hadjithomas M., Miao W. and Orias E. 2013. Selecting one of several mating types through gene segment joining and deletion in Tetrahymena thermophila. PLoS Biol. 11: e1001518. doi: 10.1371/journal.pbio.1001518.

Fishbein L. 1979. Potential industrial carcinogens and mutagens. Elsevier Scientific Publishing Company, Amsterdam, Oxford. New York.

Fishbein L., Flamm W.G. and Falk H.L. 1970. Chemical mutagens. Acad. Press, New York, London.

Holliday R. and Ho T. 2002. DNA methylation and epigenetic inheritans. Methods. 27(2), 179183. doi:10.1016/s1046-2023(02)00072-5.

Hollstein U. 1974. Actinomycin. Chemistry and mechanism of action. Chem. Rev. 74 (6), 625-652. doi:10.1021/cr60292a002.

Huijing Y., Zhengyu J., Shuoer W. and Ping Zh. 2019. Actinomycin D-activated RNase L promotes $\mathrm{H} 2$.AX/H2B-mediated DNA damage and apoptosis in lung cancer cells. Front. Oncol. 9, 1086. doi:org/103389/fonc.2019.01086.

Imamichi T., Murphy M.A, Adelsberger J.W, Yang J., Watkins C.V., Berg S.C., Baseler V.W., Lempicki R.A., Guo J., Levin G. and Lane H.C. 2003. Actinomycin D induces high-level resistance to thymidine analogs in replication of human immunodeficiency virus type 1 by interfering with host cell thymidine kinase expression. J. Virol. 77 (2), 1011-1020. doi.10.1128/JVI.77.2.1011-1020.2003.

Kalinina L.V. 1967. Hereditary changes caused by x-irradiation in Amoeba proteus. Tsitologiya. 9, 1543-1549 (in Russian with English summary).

Kalinina L.V. 1968. Hereditary changes in amoebae caused by actinomycin $\mathrm{D}$ treatment. Tsitologiya. 10, 1589-1597 (in Russian with English summary).

Kalinina L.V. 1969. A study of the resistance to streptomycin in amoebae. Tsitologiya 11, 760-767 (in Russian with English summary).

Kalinina L.V. and Yudin A.L. 1964. Genetic interaction of nuclei in heterokaryons of amoebas. Tsitologiya. 6, 695-709 (in Russian with English summary).

Kataoka K. and Mochizuki K. 2011. Programmed DNA elimination in Tetrahymena: a small RNA-mediated genome surveillance mechanism. Adv. Exp. Med. Biol. 722, 156-173.

Koba M. and Konopa J. 2005. Actinomycin $\mathrm{D}$ and its mechanisms of action. PostepyHig. Med. Dosw. 59, 290-298 (in Polish with English summary).

Lamparska K., Clark J., Babilonia G., Bedell V., Yip W. and Smith S.S. 2012. 2'-Deoxyriboguanylurea, the primary breakdown product of 5-aza-2'deoxyribocytidine, is a mutagen, an epimutagen, an inhibitor of DNA methyltransferases and an inducer of 5-azacytidine-type fragile sites. Nucleic Acids Res. 40, 9788-801. doi: 10.1093/nar/gks706.

Liu. X.F., Xiang L., Zhou Q., Carralot J.Ph., Prunotto M., Niederfellner G. and Pastan I. 2016. Actinomycin D enhances killing of cancer cells by immunotoxin RG 7787 through activation of the extrinsic pathway of apoptosis. Proc. Nat. Acad. Sci. U.S.A. 113 (38), 10666-10671. doi.org/10.1073/ pnas. 1611481113.

Maletskaia E.I., Iudanova S.S. and Maletskiı̌ S.I. 2006. Effect of the epimutagen 5-azacytidine on the structure of floral-stalk metameres in sugar beet (Beta vulgaris L). Genetika. 42, 939-46 (in Russian with English summary).

Mischo H.E., Hemmerich P., Grosse F. and Zhang S. 2005. Actinomycin D inducts histone gamma-H2AX foci and complex formation of gamma-H2 AX with Ku70 and nuclear DNA helicase II. J. Biolog. Chemisrty. 280, 9586-9594.

Miyake A. 1996. Fertilization and sexuality in Ciliates. In: Ciliates: Cells as organisms. R. Hausmann and P.C. Bradbury. Stuttgart, Jena, New 
York, Gustav Fischer Verlag, pp. 243-290.

Nanney D.L. 1958. Epigenetic control systems. Proc. Nat. Acad. Sci. U.S.A. 44, 712-716.

Nanney D.L. 1980. Experimental ciliatology. An introduction to genetics and developmental analysis in ciliates. John Wiley and Sons, New York, Chichester, Brisbane, Toronto.

Olenov J.M. 1970. Epigenomic variability. Ontogenez. 1, 10-16 (in Russian with English summary).

Siboni R.B., Nakamori M., Wagner S.D., Struck A.J., Coonrod L.A., Harriott S.A., Cass D.M., Tanner M.K. and Berglund J.A. 2015. Actinomycin D specifically reduces expanded CUG repeat RNA in myotonic dystrophy models. Cell Reports. 13, 2386-2394.

Siegel R. 1970. Genetics of mating types in ciliates. Ontogenez. 1, 157-165.

Sobell H. 1985. Actinomycin and DNA transcription. Proc. Nat. Acad. Sci. U.S.A. 82, 53285331. doi:10.1073/pnas.82.16.5328.

Takagi Y. 1988. Aging. In: Paramecium. Springer-Verlag, Berlin, pp. 131-140.

Uspenskaya Z.I. 2018. Epigenetic factors in vital functions of the ciliate Dileptus anser. Protistology. 12, 61-72. doi: 10.21685/1680-0826-2018-12-2-1.

Uspenskaya Z.I. 2019. The ciliate Dileptus anser is an object for research genetic instability in the system of serotypes and mating types. Tsitologiya. 61, 787-796 (in Russian with English summary).

Uspenskaya Z.I. and Yudin A.L. 2003. Mating types in the ciliate Dileptus anser. Genetical instability in the mating type system. Tsitologiya. 45, 510-514 (in Russian with English summary).

Uspenskaya Z.I. and Yudin A.L. 2016. Fifty years of research on serotypes and mating types in
Dileptus anser: A review. Eur. J. Protistol. 53, 31-44. doi.org/10.1016/j.ejop.2015.12.0o4.

Uspenskaya Z.I. and Yudin A.L. 2017. Actinomycin D as epimutagen in Protists. Acta Protozool. 56, 139-147. doi 10.4467/16890027 AP. 17.02.7493.

Yudin A.L. 1973. Nuclear-nuclear interactions in heterokaryons. In: The biology of Amoeba, Academic Press, New York, London, pp. 505-524.

Yudin A.L. 1979. Mechanisms of destabilization of hereditary characters in amoeba. II. Heritable variations induced by some antibiotics. Acta Protozool. 18, 571-580.

Yudin A.L. 1982. Nucleocytoplasmic relationships and cell heredity in amoebae. Nauka, Leningrad, (in Russian).

Yudin A.L. and Afon'kin S.Yu. 1987. Genetic determination and inheritance of mating types in Dileptus anser (Gymnostomatida, Holotrricha). In: Current problems of protozoology. Nauka, Leningrad, pp. 32 (in Russian).

Yudin A.L., Afon'kin S.Yu. and Parfenova E.V. 1990. Mating pheromones in the ciliate Dileptus anser. Tsitologiya. 32,107-116 (in Russian with English summary).

Yudin A.L. and Sopina V.A. 1970. On the role of nucleus and cytoplasm in the inheritance of some characters in Amoebae (nuclear transfer experiments). Acta Protozool. 8, 1-39.

Yudin A.L. and Uspenskaya Z.I. 2006. Mating types in the ciliate Dileptus anser. Inheritance and genetic determination. Tsitologiya. 48, 364-374 (in Russian with English summary).

Yudin A.L. and Uspenskaya Z.I. 2007. Nuclear differentiation for mating types in the ciliate Dileptus anser. A hypothesis. Cell Biol. Int. 31, 428-432.

Address for correspondence: Zoya I. Uspenskaya. Institute of Cytology, Russian Academy of Sciences, Tikhoretsky Avenue 4, St. Petersburg 194064, Russia; e-mail: zoyaus@mail.ru. 